\title{
VISUALIDADE, ARTE E CULTURA NOS LIVROS DIDÁTICOS
}

\author{
Katia Maria Roberto de Oliveira Kodama
}

Universidade Estadual Paulista - FCT/UNESP. Presidente Prudente - SP. E-mail: katiakodama@fct.unesp.br

\section{RESUMO}

Esse trabalho apresenta considerações vinculadas a um projeto de pesquisa que estuda a apresentação de conhecimentos sobre as Artes, Cultura e Visualidades nos materiais didáticos indicados para os primeiros anos do Ensino Fundamental das escolas públicas. Analisa se nos livros didáticos existem inferências quanto à formação em arte relacionada ao conhecimento e alfabetismo visual, e se existem propostas para desenvolver o pertencimento cultural. Assim, verificou-se sua diagramação e apresentação visual, bem como ilustrações e se observou se existem atividades que promovam a diversidade cultural do país. O letramento não exclui o conhecimento de mundo, e do local, que pode ser desencadeado pela Arte. Os livros didáticos estão presentes na maioria das escolas, porém neles não se observa um planejamento cuidadoso, o tratamento visual apresenta-se de forma incipiente e, nesse sentido, estão prestando um desserviço quanto à formação da consciência crítica dos alunos e professores.

Palavras-chave: Arte, Cultura, Livros didáticos, Visualidades, Alfabetização visual.

\section{VISUALITY, ART AND CULTURE IN EDUCATIONAL BOOKS}

\begin{abstract}
This work presents related considerations for a research project that studies the knowledge presentation about Art, Culture and Visualities in didactic materials indicated for the first years of elementary education in public schools. Examines whether the textbooks are inferences regarding the training in art-related knowledge and visual literacy, and if there are proposals to develop the cultural belonging. Therefore, it was verified its layout and visual presentation, as well as illustrations and was observed if there are activities that promote cultural diversity of the country. The information literacy does not exclude the knowledge of the world and the site, which can be triggered by Art. Textbooks are present in most schools, but is not observed in them an careful planning, the visual treatment is presented incipiently and, accordingly, are doing a disservice for the formation of critical consciousness of students and teachers.
\end{abstract}

Keywords: Art, Culture, Textbooks, Visual Arts, Visual literacy. 


\section{INTRODUÇÃO E OBJETIVO}

Ao realizar esse estudo se objetivou ampliar o referencial teórico das práticas do ensino das artes e manifestações culturais inseridos em uma realidade concreta. Assim, os apontamentos apresentados são provenientes de uma pesquisa em andamento que pretende contribuir para ampliar as reflexões acadêmicas a serem apropriadas e utilizadas pelos seus protagonistas, os agentes que promovem a educação, pois todos os envolvidos no processo educativo são portadores, reprodutores e consumidores de valores culturais/estéticos. Essa dinâmica pode e deve ser considerada no Ensino Fundamental para gerar, como propõe Paulo Freire, "Práticas Educativas Emancipadoras". (FREIRE, 1983). Uma Educação "Emancipadora” permite vislumbrar propostas de mudança social através da descodificação do mundo e da inserção consciente nele.

Logo, as relações entre as manifestações culturais visuais e as linguagens das artes que imperam na contemporaneidade, assim como as propostas de ensino, deverão se imbricar, podendo ser vistas como constitutivas de uma formação comprometida com as práticas e representações sociais das comunidades, principalmente quanto aos conteúdos culturais veiculados pelos meios massivos de difusão e comunicação, predominantemente visuais.

Por esse motivo, a expressão cultura visual refere-se a uma diversidade de práticas e interpretações críticas em torno das relações entre as posições subjetivas e as práticas culturais e sociais do olhar. Desse ponto de vista, quando me refiro neste livro à cultura visual, estou falando do movimento cultural que orienta a reflexão e as práticas relacionadas a maneiras de ver e de visualizar as representações culturais e, em particular, refiro-me às maneiras subjetivas e intra-subjetivas de ver o mundo e a si mesmo. (HERNÁNDEZ, 2007, p.22).

Ainda, sob a ótica dos estudos da cultura visual é possível compreender que as representações imagéticas, e os objetos produzidos pelas artes, cumprem a função de auxiliar no entendimento e manutenção das práticas ritualísticas e simbólicas aglutinadoras dos grupos geradores da arte e cultura visual e, principalmente, das culturas e arte brasileira. $\mathrm{O}$ texto parte do princípio de que o conhecimento das artes e da visualidade deve ser trabalhado desde os anos iniciais do Ensino Fundamental.

No Brasil, as décadas de Vargas e o período desencadeado após o golpe de 1964 foram decisivos para excluir da educação atitudes como: valorização dos sentimentos, sensibilidade, emoção e os sentidos de pertencimento vinculados às culturas regionais e locais como parte da formação das crianças (RIBEIRO, 1982). A valorização das culturas locais e de uma educação voltada para os sentimentos do homem é pouco praticada nas escolas. Paulo Freire já apontou a necessidade de se pensar a escola como um organismo conectado as realidades vividas e as 
culturas locais, "Não há educação fora das sociedades humanas e não há homem no vazio" (FREIRE, 1993, p. 43).

Vive-se o momento dialético do início de um século que não permitirá ao homem ser como antes, conclamando-o a construir um humanismo novo para o milênio em curso, numa urgência até então desconhecida pela própria história. Freire aponta para o imbricamento entre tempo e cultura/arte:

Herdamos a experiência adquirida, criando e recriando, integrando-se às condições de seu contexto, respondendo a seus desafios, objetivando-se a si próprio, discernindo, transcendendo, lança-se o homem num domínio que the é exclusivo - o da História e o da Cultura. (FREIRE, 1993, p 41).

A redenção para nosso tempo ainda está nos processos de aprendizagens, como endossa o relatório (DELORS, 2001, p.99), "a educação deve contribuir para o desenvolvimento total da pessoa - espírito e corpo, inteligência, sensibilidade, sentido estético, responsabilidade pessoal e espiritualidade.", e, propõe no mesmo texto os pilares de uma educação para o século XXI, que consiste em "aprender a conhecer", "aprender a fazer", "aprender a viver juntos" e "aprender a ser" (DELORS, 2001, p. 31).

Assim, a partir das premissas apontadas foram analisados alguns materiais didáticos destinados às escolas, procedentes da Secretaria do Estado, do Ministério da Educação e dos programas de distribuição de livros didáticos. Como a intenção desse texto não é avaliar especificamente um material, mas apontar para a necessidade de repensar a elaboração e formatação dos diversos materiais analisados, eles não serão nomeados nem informadas as escolas que os adotam.

Portanto, este texto objetiva analisar como são apresentados, nos materiais didáticos, conhecimentos de arte e cultura visual nos primeiros anos do Ensino Fundamental nas escolas públicas. Analisa, ainda, se suas concepções visuais promovem uma alfabetização visual.

\section{CONSIDERAÇÕES SOBRE OS LIVROS DIDÁTICOS}

As considerações apresentadas sobre os livros didáticos abordarão três aspectos: diagramação e apresentação visual, ilustrações e a possibilidade de ser um disparador dos valores culturais das comunidades escolares. Essas considerações foram fundamentadas após a realização de leituras e fichamentos dos autores citados ao longo do texto e uma análise qualitativa dos materiais destinados às Escolas Públicas de Presidente Prudente. Foram priorizados os anos 
iniciais do Ensino Fundamental. Assim após implementar as estratégias metodológicas citadas é possível afirmar que, até o presente, as análises demonstram:

Quanto à diagramação e apresentação visual pode-se afirmar que os livros são extremamente pobres. Como consequência, não estimulam seus usuários, professores e alunos, pois não convidam e ou acolhem os leitores. Empregam recursos elementares de diagramação e seu colorido é pouco trabalhado. No livro "Sintaxe da Linguagem Visual", DONDIS (2007, p. 23) salienta que a cor é "a contraparte do tom com o acréscimo do componente cromático, o elemento visual mais expressivo e emocional". O autor indica ainda que essas informações foram ampliadas pelos estudos elaborados pela psicologia da Gestalt. Nesta perspectiva fica a pergunta: Como a criança, e mesmo o professor, podem ter prazer em manipular um livro sem atrativos visuais.

No Brasil, os programas educacionais são fartos em distribuir livros cujos conteúdos visuais são simplistas. Essa proposta econômica, e sem recursos, está na origem dos materiais didáticos elaborados no início do século $X X$, quando as gráficas não dispunham de recursos tecnológicos e os custos de se produzir materiais impressos eram elevados no país.

Como consequência, os livros didáticos eram pouco elaborados e despojados visualmente. Para suprir essa escassez, os futuros professores tinham uma disciplina denominada Desenho Pedagógico, nas Escolas Normais e Institutos de Educação, onde aprendiam os rudimentos de desenho e alguns esquemas de construção de imagens para ilustrar suas aulas, essas ilustrações também seguiam os padrões das cartilhas.

As cartilhas foram e são importantes difusoras das imagens encontradas na maioria dos materiais didáticos da atualidade. A Cartilha Proença era editada em Portugal e a partir de 1926 foi importada e adotada transformando-se no material didático mais usado no país. Nas décadas de 40 e 50, a cartilha Caminho Suave preconizava "Alfabetizando pela Imagem" e estabeleceu uma diagramação e estética ainda mantida na atualidade.

Essa visualidade do Desenho Pedagógico e das Cartilhas é predominante nos livros analisados: muitos textos, poucas e pobres imagens, muitos monocromáticos, e, quando há colorido, os desenhos são simplistas.

Quanto às ilustrações, são precárias, e reproduzem os esquemas do Desenho Pedagógico. No livro Metodologia do Ensino de Arte, as autoras Ferraz e Fusari (1983) abordam o assunto, indicam que um dos livros mais usados para esse fim foi o "Manual de Desenho Pedagógico", de José Arruda Penteado, e a coleção "Desenhos Artísticos Pedagógicos”, de Cláudia Joquebede S. Borges. 
Esses são "clássicos" exemplos da estética ainda adotada pela escola em todos os seus aspectos visuais e nos livros didáticos utilizados atualmente. A estética presente nos livros didáticos analisados tem norteado os professores no planejamento dos arranjos visuais de suas salas e de outras atividades, como as datas comemorativas e na própria organização espacial das escolas.

Nesse sentido, é fundamental ressaltar que a estética dos desenhos pedagógicos não está presente no dia a dia das crianças, pois é evidente que as publicidades, e a própria televisão que sobrevive da sedução para gerar o consumo, não podem e não criam nada tão pobre como os desenhos dos materiais didáticos. Agindo deste modo, a escola presta uma enorme contribuição para esses meios de difusão de informações e formação de consumidores ao perpetuar uma estética tão fora da realidade de seus alunos. Nada é tão sem conteúdo visual como os desenhos e ilustrações presentes nas escolas.

Nessa perspectiva, fica a indagação: Como se sentir fascinado pela sala de aula se o cartaz da esquina é mais atrativo? Como afirma MORAN (2008, p. 07), "a escola é pouco atraente". Essas considerações não são apresentadas neste texto para defender a estética do consumo, mas para demonstrar como a escola está descontextualizada.

Quanto à possibilidade de ser um disparador dos valores culturais das comunidades escolares é possível inferir que, nesse mundo globalizado e imagético, a arte é, segundo Lucia Santaella, o veículo comunicacional que está impregnado de síntese do presente, mas que sempre aponta para o futuro, pois se encontra próximo dos "enigmas do real". Essa autora ainda afirma que, nos tempos mutantes da atualidade, os artistas fornecem as explicações mais imediatas "pelo simples fato de que, parafraseando Lacan, eles sabem sem saber que sabem." (SANTAELLA, 2003, p. 31).

As manifestações das artes são sempre um acontecimento coletivo, pois envolvem, necessariamente, um produtor ou produtores, o contato com diferentes saberes e ofícios, e um receptor ou receptores. São compostas por um conjunto formal de procedimentos tecnológicos e atitudes que refletem as formas de pensar e agir de uma comunidade.

Desta forma, sob a ótica dos estudos de cultura visual, é possível compreender que as representações imagéticas e os objetos produzidos pelas artes cumprem dupla função: auxiliar no entendimento e perpetuação das práticas ritualísticas e simbólicas aglutinadoras dos grupos geradores das culturas, e, propiciar uma reflexão crítica sobre as inúmeras conceituações empregadas para compreender e classificar os gêneros das múltiplas linguagens de expressões artísticas presentes na atualidade. 
A educadora e pesquisadora de Arte, Ana Mae Barbosa, aponta para essa diversidade cultural e para a tendência da escola de excluir o conhecimento das artes, suas linguagens e suas múltiplas manifestações.

O que temos, entretanto, é o apartheid cultural. Para o povo, o candomblé, o carnaval, o bumba-meu-boi e a sonegação de códigos eruditos de arte que presidem o gosto da classe dominante que, por ser dominante, tem possibilidade de ser mais abrangente e também domina os códigos da cultura popular. [...] 0 intercruzamento de padrões estéticos e o discernimento de valores devia ser o princípio dialético a presidir os conteúdos da aprendizagem da arte, através da magia do fazer, da leitura deste fazer e dos fazeres de artistas populares e eruditos, e da contextualização destes artistas no seu tempo e no seu espaço. (BARBOSA, 1991, p.33)

Nesta perspectiva, Ana Mae afiança um bom ensino de Arte e defende que os estudos da cultura visual devem acompanhar a formação do educador e ser apresentado para os pequenos: "porque é impossível o desenvolvimento integral da inteligência sem o desenvolvimento do pensamento divergente, do pensamento visual e do conhecimento presentacional que caracterizam a arte". (BARBOSA, 1991, p. 5).

\section{OUTROS CONHECIMENTOS}

$\mathrm{Na}$ atualidade as relações com a visualidade é vital. A comunicação visual não é um fenômeno isolado, nem restrito à contemporaneidade, pois interage com as manifestações culturais de cada comunidade desde seus primórdios. Para entender os diferentes processos comunicacionais visuais é necessário entender o local da cultura. Portanto, é necessário olhar para uma:

[...] ancoragem territorial de inserção no local, já que é no lugar, no território que se desenrola a corporeidade da vida cotidiana e a temporalidade - a história - da ação coletiva, base da heterogeneidade humana e reciprocidade, características fundadoras da comunicação humana (BARBERO in MORAES, 2003, p.58).

A velocidade com que as informações são produzidas cria uma macrocircularidade de informações e força os pesquisadores da Teoria da Comunicação, da Cultural Visual, das Artes e da Educação a voltarem sua atenção para o local.

[...] mesmo atravessado pelas redes do global, o lugar segue feito de tecidos das proximidades e das solidariedades. Isso exige que se esclareça que o sentido do local não é unívoco. Um é aquele que resulta da fragmentação produzida pela deslocalização que o global acarreta, e outra é a revalorização do local como âmbito onde se resiste (e se complementa) a globalização, sua auto- 
revalorização como direito à autogestão e à memória própria, ambos ligados à capacidade de construir relatos e imagens de identidade. (BARBERO in MORAES, 2003, p.58-59).

Conforme as concepções acima apresentadas, os livros didáticos analisados não contribuem para inserir e nem promover uma educação que vá ao encontro de uma formação atualizada. Existe uma contradição entre o que se propõem e como são elaborados e diagramados. Há uma limitação ao propor que a formação da criança deva se pautar exclusivamente na aquisição da escrita e leitura, desprezando a realidade visual contemporânea. Para atingir uma educação plena é necessário que os suportes pedagógicos e os materiais de apoio se modifiquem.

A escrita e leitura são fatores decisivos para a compreensão do mundo hegemônico da acadêmica, mas para a hegemonia econômica e das informações midiáticas é necessária à incorporação dos estudos culturais e visuais nas propostas educativas, ou seja, de um alfabetismo visual. Um caminho assertivo para promover essas competências é o conhecimento que as artes oferecem.

Deste modo é possível afirmar que a apresentação e a concepção visual dos livros e materiais didáticos destinados às escolas estão aquém do necessário para cumprir seus propósitos de promover uma aprendizagem efetiva.

Os livros analisados até o momento são de uma concepção visual primária e foi possível detectar que: a) não fazem uso de obras de arte, os desenhos são estereótipos dos desenhos pedagógicos, a diagramação é elementar e pouco atrativa, as ilustrações das histórias não apoiam as narrativas; b) raramente existem indicativos de propostas para explorar outros livros de imagens ou são apresentadas propostas que indiquem aos professores como eles podem utilizar outros recursos, em outras mídias, destinados à escola; c) são poucas as indicações para que os educadores utilizem conteúdos presentes nos inúmeros sites sobre cultura e arte, geralmente gratuitos, ou apresentem o trabalho de artistas. Também não foram encontrados materiais ilustrados e ou diagramados com o mesmo cuidado detectado em muitos livros de literatura infantil e juvenil.

Nesse sentido, é importante salientar que os livros didáticos estão prestando um desserviço na formação da consciência crítica dos alunos e professores, pois como afirma Moran;

Pela primeira vez na história, percebemos que a educação não acontece só durante um período determinado de tempo, maior ou menor (educação básica, superior), mas ao longo da vida de todos os cidadãos e em todos os espaços. [...] As sociedades sempre encontraram suas formas de educar. Quanto mais 
avançadas, mais complexas se tornam seus processos de ensinar. (MORAN, 2008, p 15).

Portanto, o presente trabalho, e a pesquisa em andamento, são motivados pelo desejo de contribuir para a ampliação das ofertas de formação através da imagem e da arte, para que promovam as culturas das comunidades, enriquecendo o vocabulário das crianças, apresentando outras possibilidades estéticas que possam suscitar escolhas e ampliação das noções de alfabetização visual e pertencimento cultural. Afinal, como afirma MORAN (2008, p. 22): “A escola e a universidade precisam reaprender a aprender, a ser mais úteis, a prestar serviços mais relevantes à sociedade, a sair do casulo em que se encontram".

\section{REFERÊNCIAS}

BARBOSA, A. M. A Imagem no Ensino da Arte: anos 80 e novos tempos. São Paulo: Editora Perspectiva, 1991.

BORGES, C. J. S.; MENDONÇAS, W. D. Desenhos Artísticos Pedagógicos: Atividades Coordenação Motoras (recortar, Colar, Colorir, Enfeitar), Uberlândia: Editora Gráfica Claranto Ltda - sem data.

DELORS, J. Educação: um tesouro a descobrir. Brasília, DF: Unesco, 2001. Relatório para a Unesco da Comissão Internacional sobre Educação para o século XXI.

DONDIS, D. A. Sintaxe da Linguagem Visual. Trad. Jefferson Luiz de Camargo. São Paulo: Martins Fontes, 2007.

FERRAZ, M. E.; FUSARI, M. F. de R. Metodologia do Ensino de Arte. São Paulo: Cortez, 1993.

FREIRE, P. Educação e mudança. 21 ed. Rio de Janeiro: Paz e Terra, 1993.

. Educação como Prática da Liberdade. 15 ed. Rio de Janeiro: Paz e Terra, 1983.

HERNÁNDEZ, F. Catadores da Cultura Visual. Proposta para uma narrativa educacional. Porto Alegre: Mediação, 2007.

MORAN, J.M. A educação que desejamos: novos desafios e como chegar lá. 3 ed. Campinas: Papirus, 2008.

MORAES, D. de (org). Por uma outra comunicação: mídia mundialização cultural e poder. 2 ed. Rio de Janeiro: Record, 2003.

PENTEAdO, J. A. Manual de. Desenho Pedagógico: para as Escolas Normais e Institutos de Educação. São Paulo: Companhia Nacional, 1958.

RIBEIRO, M. L. S. História da Educação Brasileira: a organização escolar. 4 ed. São Paulo: Moraes, 1982. 
SANTAELLA, L. Da cultura das mídias à cibercultura: o advento do pós humano. Rev. FAMECOS, Tecnologias Do Imaginário. Porto Alegre. no 22. Dez. 2003, p. 23 - 32, quadrimestral, 2003. Disponível em: http://www.sharepdf.com/b6b20091766f4b138ad95 ecc1c57966/3229-10605-1-PBSantaella.htm. Acesso em: 25/05/2014. 